Volume 5, Issue 3, October 2020, pp. 231-246

DOI: $10.23917 /$ jramathedu.v5i3.10962

p-ISSN: 2503-3697, e-ISSN: 2541-2590

\title{
Distributivity, partitioning, and the multiplication algorithm
}

\author{
Chris Hurst ${ }^{*}$, Ray Huntley² \\ ${ }^{1}$ School of Education, Curtin University, Australia \\ ${ }^{2}$ Freelance Researcher, Plymouth, United Kingdom \\ *Corresponding author: c.hurst@curtin.edu.au
}

\begin{tabular}{l}
\hline ARTICLE INFO \\
\hline Article history: \\
Received: 25 May 2020 \\
Revised: 11 July 2020 \\
Accepted: 12 July 2020 \\
Published online: 16 July 2020 \\
Published regularly: October \\
2020
\end{tabular}

ABSTRACT

Multiplicative thinking underpins much of the mathematics learned beyond the middle primary years. As such, it needs to be understood conceptually to highlight the connections between its many aspects. This paper focuses on one such connection; that is how the array, place value partitioning and the distributive property of multiplication are related. It is important that students understand how the property informs the written multiplication algorithm. Another component of successful use of the standard multiplication algorithm is extended number facts and the paper also explores students' ability to understand and generate them. One purpose of the study was to investigate the extent to which students used the standard multiplication algorithm and if their use of it is supported by an understanding of the underpinning components of the

Keywords:

Multiplicative, conceptual, procedural, algorithm, array, partitioning, the distributive property, and extended number facts. That is, we seek to learn if students have a conceptual understanding of the multiplication algorithm and its underpinning mathematics that would enable them to transfer their knowledge to a range of contexts, or if they have procedurally learned mathematics. In this qualitative study, data were generated from the administration of a Multiplicative Thinking Quiz with a sample of 36 primary aged students. Data were analyzed manually and reported using descriptive statistics. The main implications of the study are that the connections among the multiplicative array, place value partitioning, base ten property of place value, distributive property of multiplication, and extended number facts need to be made explicit for children in terms of how they inform the use of the written algorithm for multiplication.

(C) 2020 Universitas Muhammadiyah Surakarta

\section{Introduction}

As one of the 'big ideas' of mathematics (Hurst \& Hurrell, 2014; Siemon, Bleckley, \& Neal, 2012), multiplicative thinking is characterized by a complex set of connected ideas (Hurst \& Hurrell, 2016) which facilitate the learning of much of the mathematics from middle primary years onwards. The Australian Curriculum, Assessment, and Reporting Authority (2020) alludes to the importance of such connected mathematical thinking in describing the proficiency of Understanding as involving adaptable and transferable mathematical concepts upon which students can build a conceptual level of understanding.

To cite this article:

Hurst, C., \& Huntley, R. (2020). Distributivity, partitioning, and the multiplication algorithm. JRAMathEdu Uournal of Research and Advances in Mathematics Education), 5(3), 231-246. doi: https://doi.org/10.23917/jramathedu.v5i3.10962 
Thinking multiplicatively is very much dependent on understanding the connections between ideas and how they underpin mathematical procedures.

Researchers (Clark \& Kamii, 1996; Siemon, Breed, Dole, Izard, \& Virgona, 2006) have noted that students who do not think multiplicatively have considerable difficulty in comprehending higher level concepts such as fractions, proportional reasoning, and algebra. This link underlines the vital importance of teachers understanding how the various elements of multiplicative thinking are connected so that they can make such connections explicit for students. The following definition (Hurst, 2017) is based on the

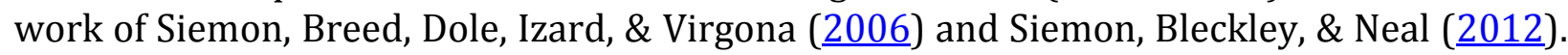
Multiplicative thinking is demonstrated by an ability to

- Work flexibly with a wide range of numbers including very large and small whole numbers, decimals, fractions, ratio and percentage;

- Work conceptually with the relative magnitude of whole and decimal numbers in a range of representations, demonstrating an understanding of the notion of 'times as many';

- Demonstrate a conceptual understanding of the multiplicative situation, the relationship between multiplication and division, numbers of equal groups, factors and multiples, and the various properties of multiplication; and

- Articulate a conceptual understanding of a range of multiplicative ideas in a connected way with explicit language and terminology (Hurst, 2017).

Skemp's 1976 seminal paper highlighted the importance of relational understanding where connections among aspects of mathematical structure are evident and used by children. It can be equated with conceptual understanding described by Rittle-Johnson and Schneider $(\underline{2015})$ as a linking web of relationships. This linking might be concerned with connecting two previously known ideas or relating one newly learned concept to one that was already known. (Rittle-Johnson, Fyfe \& Loehr, 2016). The links between ideas are considered to be at least as important as the aspects of structure that they connect (RittleJohnson and Schneider, 2015). Earlier, Anthony and Walshaw (2009) discussed the importance of children understanding mathematical structure through realizing how ideas are connected and explaining those connections. Hence conceptual understanding involves much more than knowing isolated aspects of knowledge. Rather it is about children seeing how ideas are connected through teachers making such connections explicit to them.

If students are to work flexibly with a range of numbers, we believe that there must be explicit teaching of the many connections within the broad idea of multiplicative thinking in order to develop conceptual understanding. However, Richland, Stigler and Holyoak (2012) note that many schools are not teaching a conceptual understanding of mathematics to their students, something which could support these students in their capacity to transfer and generalize the mathematics they are learning. Specifically, in this paper, we explore students' understanding of arrays, possible links between partitioning based on place value and the distributive property of multiplication, and identification and generation of extended multiplication facts. As well, we consider students' use of written algorithms and associated methods in the light of their understanding of the abovementioned factors.

Primary/Junior School students are expected to use the standard written algorithm for the multiplication of multi-digit numbers (ACARA, 2017; NGA Centre, 2010). It seems reasonable to think that using the algorithm should be preceded by an understanding of why it works through an understanding of the mathematical structure that underpins it. There are several aspects of mathematical structure that fit that description - the array, and place value partitioning, both of which directly inform an understanding of the 
distributive property of multiplication, and the base ten property of place value, which informs the generation of extended number facts. The distributive property and the use of extended number facts then inform an understanding of the written algorithm.

Various mathematics researchers and educators (Haylock, 2014; Squire, Davies, and Bryant, 2004; Turton, 2007) have described the distributive property as distributing the multiplication operation over the addition of the parts of a number. Symbolically, it is represented as $(\mathrm{a}+\mathrm{b}) \times \mathrm{c}=(\mathrm{a} \times \mathrm{c})+(\mathrm{b} \times \mathrm{c})$. Haylock noted that people may not have realized that the distributive property underpins the multiplication algorithm, yet they have been unconsciously using the algorithm for many years. Benson, Wall and Malm ( $\underline{2013})$ suggested that students as young as Grade 3 have an intuitive understanding of area conservation when using arrays. They are readily able to understand that a5 x 12 array can be seen as $5 \times(3+4+5)$. This suggests that they have a conceptual understanding of the distributive property where multiplication is distributed over addition, one of the key ideas in using the formal multiplication algorithm. By following a developmental progression from arrays through the grid method to the formal algorithm, students understand better the purpose of the algorithm by understanding the component sub-structures on which it is built.

Matney and Daugherty ( $\underline{2013}$ ) also suggested that the array is a useful pre-requisite to ideas of commutativity and distributivity, and that manipulation of arrays offers the valuable experience of recognizing efficient ways of grouping numbers and links to the partial products needed for the algorithm. By offering students dot arrays for grouping, they are encouraged to seek efficient and fluent methods for counting the dots.

The array can be used to develop an understanding of the distributive property which informs the grid method for multi-digit multiplication. It should be used with smaller numbers such as two digits multiplied by one digit (e.g., $14 \times 9$ ) and once an understanding of that is developed, the grid method can be used for larger numbers. This development is shown in Figure 1. The standard algorithm can then be developed and used on the basis of understanding the distributive property.

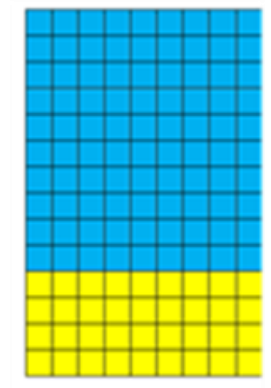

$14 \times 9=(10 \times 9)+(4 \times 9)$

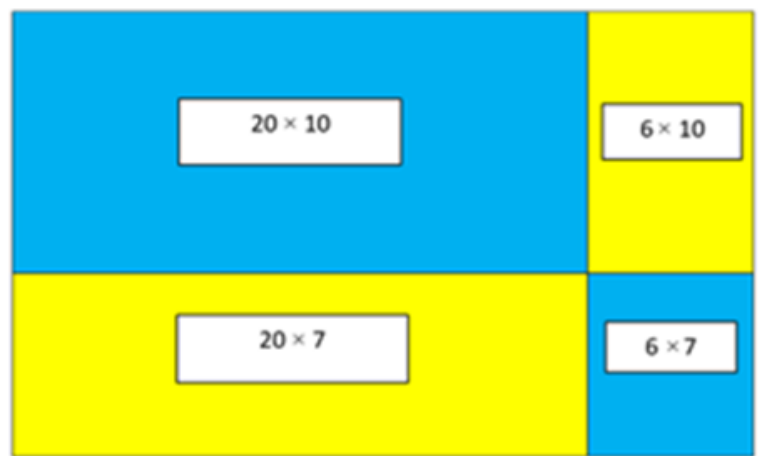

$26 \times 17=(20 \times 10)+(20 \times 7)+(6 \times 10)+(6 \times 7)$

Figure 1. Progression from array showing the distributive property to grid method

The distributive property of multiplication could be considered the key to understanding the vertical multiplication algorithm which is taught in a range of ways by teachers. In describing the importance of this property, Kinzer and Stafford (2013) discussed partitioning. They noted that it is a critical part of enabling students to make sense of multiplication through an understanding of the distributive property. Kinzer \& Stafford (2013, p. 308) also linked the importance of the array in developing an understanding of the distributive property, noting how it helped reduce relatively complex 
calculations to simpler ones. Their view supports the Common Core State Standards for Mathematics (NGA Centre, 2010) which also underlines the importance of the link between multiplication and the array, and hence the distributive property.

Various other researchers have noted the importance of the underpinning mathematics being discussed here. Norton \& Irvin (2007) said that concepts such as the distributive law underpin algebraic thinking and must, therefore, be emphasized in the primary years. Young-Loveridge $(\underline{2005})$ identified that part-whole strategies for multiplicative thinking allow for flexible and efficient methods when solving, for example, 6 $\times 24$. This can be seen as $6 \times 20$ added to $6 \times 4$, or perhaps as $6 \times 25$ and subtract 6 . Known number facts (perhaps $6 \times 10$ or $6 \times 20)$ can be shaded on an array, and other facts $(6 \times 4)$ can be identified from what remains. The answers to the number facts are then combined to produce a total. The quality of understanding about multiplication that results from knowing about the distributive property is further noted by Young-Loveridge \& Mills (2009). They said that multiplication strategies based on partitioning and the distributive property are more advanced than those based on other ideas such as repeated addition. Given these points, it is interesting to note that, in his discussion of the distributive property, Haylock (2014) did not use the term 'partition' but rather described it in terms of 'breaking up' the number. However, other mathematics educators (Thompson, 2003; Askew, 2012; Cotton, 2016; Lemonidis, 2016) specifically use the term 'partitioning' when describing computational strategies used by children. Indeed, Cotton discusses children's efforts to explain how they partitioned three-digit numbers when multiplying them. This suggests that if children are to be taught such strategies, they should be encouraged to use appropriate terminology.

Kaminski (2002) studied how a group of pre-service primary teachers used the distributive property in flexible ways when solving multiplication exercises. He made an interesting observation that some of the pre-service teachers were aware of the property, many others did not know how it was applied to multiplication. Kaminski's sample consisted of pre-service teachers, as opposed to in-service teachers, but his observation begs the question as to whether or not the majority of in-service teachers would be clear about how the distributive property can be applied. Perhaps the same situation might apply to realize (or not realize) the connection between place value partitioning and the distributive property.

Ross ( $\underline{2002}$ ) described the base ten property of place value as showing how the places increase by a power of ten moving from right to left. This understanding, combined with a knowledge of basic multiplication facts, enables students to generate extended number facts where one or more of the factors are increased by a power/s of ten. The associated understanding is that if one factor is increased by a power of ten, then so must the product (or multiple). The ability to generate extended number facts helps students understand the standard multiplication algorithm (see Figure 2). In particular, they understand that the placement of a zero in the second line signifies $26 \times 10$ and not $26 \times 1$, and that the product must be ten times greater than 26. Jazby and Pearn (2015) suggested that algorithms are used to minimize the cognitive load as they break up a complex calculation into several more easily managed sections. However, they identified an interesting issue surrounding the teaching of algorithms. If they are taught procedurally, a student can 'suspend place value' (Jazby \& Pearn) and would carry out the final part of the calculation in Figure 2 as 2 $\times 1$. However, to fully understand what is happening in the algorithm, and why an answer might be correct or otherwise, a student needs to know that the ' $2 \times 1$ ' really represents ' 2 tens $\times 1$ ten' or ' $2 \times 1 \times 10 \times 10$ ' and that the result must be 100 times greater than 2 . 


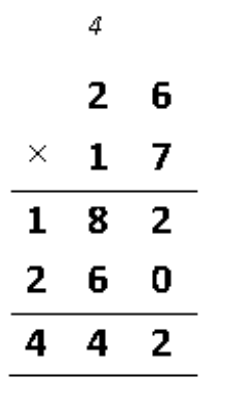

Figure 2. Standard multiplication algorithm

\section{Theoretical Framework}

There appear to be some clear links between the use of the array, an understanding of place value partitioning (Jazby \& Pearn, 2015), and the distributive property (Matney \& Daugherty, 2013; Kinzer \& Stafford, 2015). Similarly, it is reasonable to suggest that the base ten property of place value underpins the use of extended number facts (Ross, 2002). Both of the distributive property and extended facts then underpin the understanding and efficient use of the standard multiplication algorithm. Pickreign and Rogers (2006) also noted the connection between the area or grid model for multiplication and the array, as the basis for understanding the algorithm. They stating that, "Connecting the array model of multiplication to an area model for multiplication has a certain appeal" (Pickreign \& Rogers, 2006 , p. 43). These links form the theoretical framework for this study. It is presented here in Figure 3.

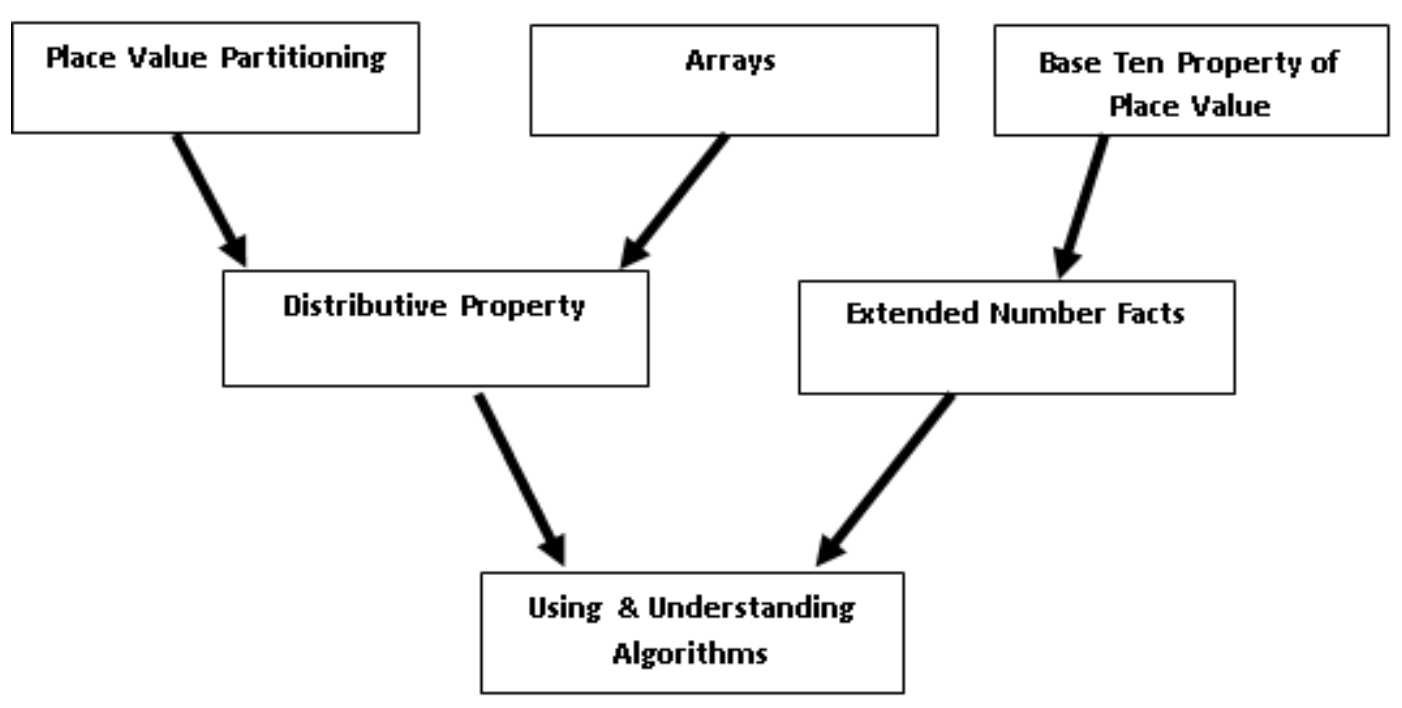

Figure 3. Theoretical framework for the study

Hurst and Hurrell (2018a) noted that developing the algorithm through the connections described takes time and effort, but this is time well invested and can minimize the need for later remediation. Hurst and Hurrell (2018b) also described several learning pathways for developing a conceptual understanding of the algorithm. In this light, it was decided to seek an answer to this research question: To what extent can primary school students correctly use a written multiplication algorithm, and demonstrate a conceptual understanding of the mathematics that underpins its use? As noted earlier, conceptual understanding is characterized by links and relationships. The study sought to 
learn the extent to which children had a 'connected view' of the mathematical structure and were able to explain what they were doing in terms of one or other aspects of the structure.

\section{Research Methods}

This paper reports on a part of an on-going study into multiplicative thinking of children from 9 to 11 years of age, which has been conducted over four years. The main data gathering instrument is a written Multiplicative Thinking Quiz (MTQ). This has generated data about a range of aspects of multiplicative thinking, including multiplication properties, and multiplicative relationships. As well, a semi-structured interview has been used to gather supporting data and to probe children's thinking. This sample comprises 36 children from two primary school classes at one school in the south-west of the United Kingdom. One of the researchers was based in the same city as the school and had approached the headmaster about involving his school in the project. The researchers administered the quiz to both classes on the same day under identical conditions with no time limits. Follow up interviews were conducted by the researchers with those children for whom consent was obtained. Interviews took about twenty minutes and were audiorecorded. Both the MTQ and the interview format had been trialled with a range of children in Western Australian schools.

The sample comprised 15 Year 5 students and 21 Year 6 students with a range of mathematical ability. The Year 5 teacher was a teacher of over twenty years of experience whilst the Year Six teacher was in his second year of teaching. The school mathematics policy states that children in Years 5 and 6 should be able to multiply numbers up to four digits and beyond by a one- or two-digit number using a formal written method, including long multiplication of two-digit numbers. As the data gathering was conducted during the second half of the school year, children would have had exposure to the written algorithm. Data from the MTQ were recorded on an Excel spreadsheet and tallied using the 'sum' function. Interviews were manually transcribed and common themes were identified from the responses. In the MTQ, students were asked a total of 18 questions, six of which are based on aspects of the framework (see Figure 3). They are shown below.

\section{Arrays}

The purpose of this question was to see if children drew a tightly aligned array or depicted $4 \times 3$ as separate groups. We wanted to see if they were familiar with arrays.

1a) What is the answer to $4 \times 3$ ?

b) Use dots, crosses or something similar and draw a picture to show what $4 \times 3$ means.

\section{Partitioning}

The purpose of these questions was to see if children used standard place value partitioning to work out the answer. This could be shown by 'carrying the 4' or by using partial products. We also wanted to see if they used the specific term 'partition'.

18. a) Can you work out the answer to $6 \times 17$ in your head? If so, what is the answer?

b) Please explain how you worked it out.

19. a) What is the answer to $9 \times 15$ ?

b) How did you work it out? 


\section{Distributive property}

This question was designed to see if children could correctly identify both instances of where the distributive property was correctly applied. The second part of the question was designed to see if they could explain how the property worked in terms of partitioning.

20. Which of the following will give you the same answer as $89 \times 3$ ?

a) Write 'Yes' or 'No' underneath each one.

b) Give a reason for two of your choices of a 'Yes' or 'No' answers.

\begin{tabular}{|l|l|l|l|}
\hline $83 \times 9$ & $(80 \times 3)+(9 \times 3)$ & $(80 \times 9)+(3 \times 9)$ & $(90 \times 3)-(1 \times 3)$ \\
\hline & & & \\
\hline
\end{tabular}

\section{Extended number facts}

The purpose of the first question was to find out if children could recognize that all four extended number facts could be generated from $24 \times 6=144$. The second question sought to determine if they could write extended multiplication and division facts. This paper only considers the responses for multiplication facts as the inverse relationship between multiplication and division is not a focus of the paper.

9. If you know that the answer to $24 \times 6=144$, which of the following must you also be able to work out from that?

a) Write 'Yes' or 'No' underneath each one.

b) Give a reason for two of your choices of a 'Yes' or 'No' answer.

\begin{tabular}{|l|l|l|l|}
\hline $240 \times 6$ & $2400 \times 6$ & $240 \times 60$ & $24 \times 60$ \\
\hline
\end{tabular}

10. If you know that the answer to $7 \times 5=35$, then you might work out that

$70 \times 5=350$.

a) Write four multiplication number facts and four division facts that you might also work out from $7 \times 5=35$, with their answers.

b) Explain how you know that you can work out those facts.

The multiplication algorithm

During the interview, children were asked to show how they would work out the answer to $29 \times 37$.

\section{Results and Discussion}

A summary of the responses to the questions is presented in Table 1. Responses for the Year 5 and Year 6 students are shown separately and recorded as percentages. It is clear that the percentage of correct responses varied considerably from question to question and between year levels for approximately half of the questions. While the highest proportion of correct responses in both groups was for the use of place value partitioning, the lowest proportion of correct responses for the Year 5 group explained the distributive property in terms of partitioning. For the Year 6 group, the lowest proportion of correct responses explained the extension of number facts (19\%) yet $52 \%$ were able to generate extended facts. These points of difference will be discussed later. It is also worth noting a high proportion of Year 5s (87\%) used an algorithm or grid method to calculate the answer for $29 \times 37$ and that $71 \%$ of the Year 6 s did so. However, many students were unable to 
identify ideas that underpin the algorithm or provide satisfactory explanations for those ideas. Sample responses will now be provided for each question area.

Table 1

Summary of responses from Year 5 and 6 students shown as percentages

\begin{tabular}{lll}
\hline Question & Year 5 & Year 6 \\
\hline Used an array to depict the expression $4 \times 3$ & 73 & 38 \\
Used place value partitioning for either 6 × 17 or 9 15 & 93 & 90 \\
Identified only the two correct examples of distributive & 47 & 48 \\
property & & \\
Explained distributive property in terms of partitioning & 13 & 38 \\
Identified all four examples as extended number facts & 47 & 33 \\
Explained extension of facts based on powers of ten & 40 & 19 \\
Generated at least 3 extended multiplication facts & 60 & 52 \\
Correctly calculated the answer for 29 $\times 37$ & 87 & 71 \\
\hline
\end{tabular}

\section{Arrays}

It can be seen that $73 \%$ of the Year 5 students drew an array, but only $38 \%$ of the Year 6 students did so. This is likely due to the fact that students use symbols more than physical representations as they progress through school. Figure 4 shows typical responses to this question.

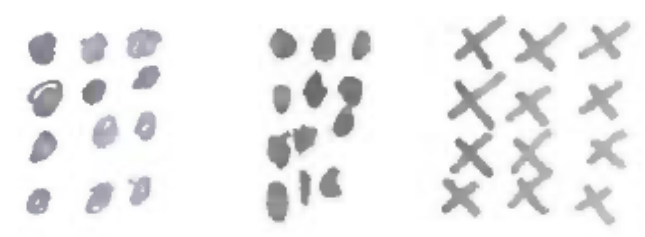

Figure 4. Typical arrays drawn by students

The connection between the array and the multiplication algorithm has already been noted (Hurst \& Hurrell, 2018a, 2018b) and there are times when the use of the array can help children who are struggling to understand distributivity and/or the written multiplication algorithm.

\section{Partitioning}

Almost all students in both classes indicated that they had partitioned the two-digit number to calculate the answer. Some used the term 'partitioned' when explaining what they did. Figure 5 shows samples from Students RCO (left) and EMA(right).
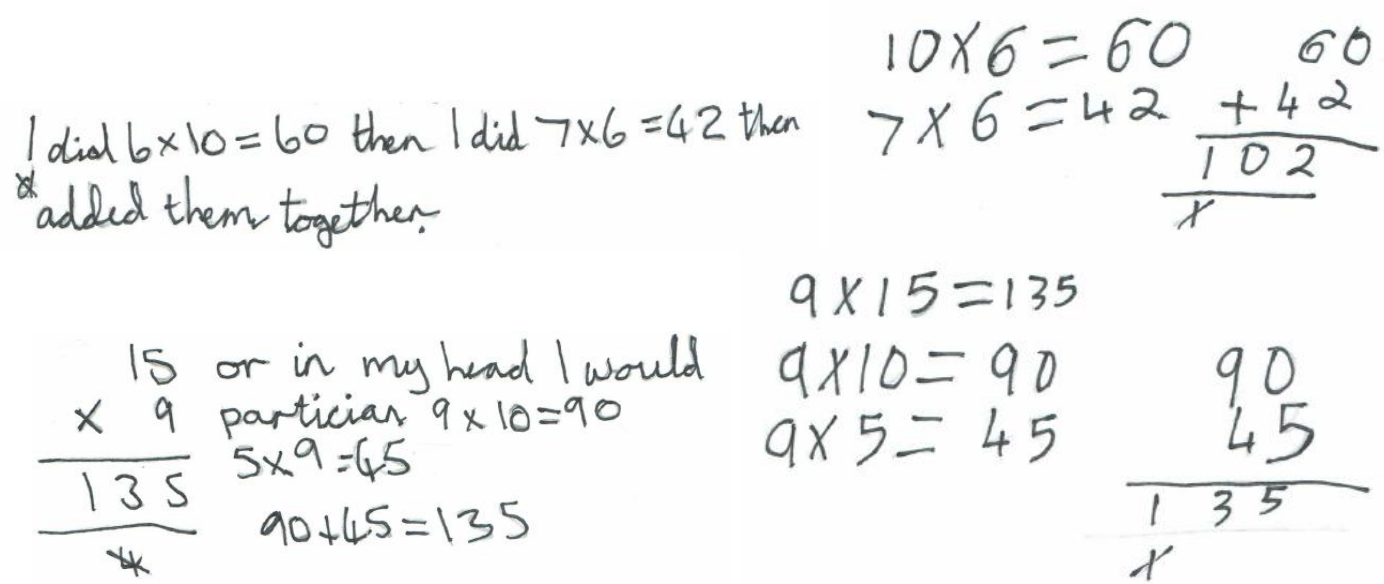

Figure 5. Samples showing partitioning by Students RCO and EMA

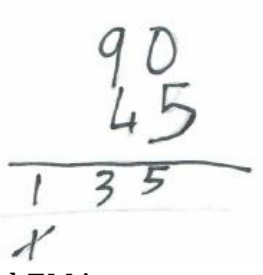


Although most students (87\% of Year 5s and $90 \%$ of Year $6 \mathrm{~s}$ ) used partitioning in that way, only $40 \%$ of Year $5 \mathrm{~s}$ and $48 \%$ of Year $6 \mathrm{~s}$ used their understanding to identify correct applications of the distributive property. It seems that about half of those students who used partitioning did not connect that the distributive property relies on partitioning.

\section{Distributive property}

As noted above, not all students who used partitioning to calculate answers for $6 \times 17$ or $9 \times 15$ correctly identified instances of the distributive property. However, every student who did identify the two correct applications of distributivity did use partitioning. As well, all students who explained how the distributive property works did so in terms of partitioning. In other words, some students appear to have connected the two ideas and some have not. Figure 6 shows samples from Students IIS and DMA.

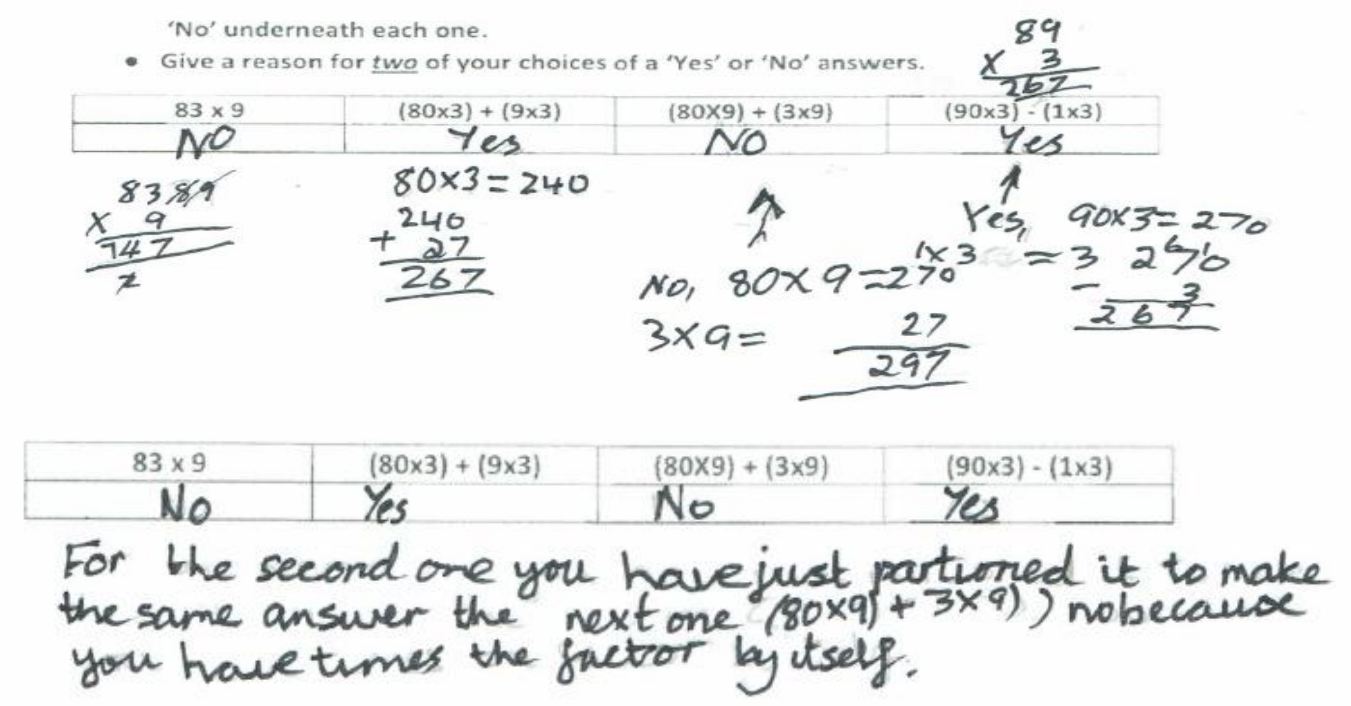

Figure 6. Samples from Students IIS and DMA

The sample from Student DMA is particularly interesting. DMA was one of four students who correctly identified the two applications of the distributive property, but found it necessary to do the calculation to ensure that the second and fourth options gave the same answer as $89 \times 3$. It is also possible that students who did so worked out the answers prior to making their selections. If this were the case, the proportion of students who identify and trust the distributive property would be less than $40 \%$ and $48 \%$ respectively for Year 5 and 6 groups.

\section{Extended number facts}

The first question was purposefully worded with all of the four options being correct. This was done to determine if students' understanding was robust because, if they assumed that there had to be at least one incorrect option, their response would be wrong. It is not known how many students made such an assumption. Responses to these two questions indicated that more students $(60 \%$ and $52 \%$ respectively for Years 5 and 6$)$ were able to write at least three extended multiplication facts than were able to identify them (47\% and 33\% respectively). As well, less could explain why extended number facts worked (40\% and 19\% respectively). The fact that more students could write extended facts than could explain how they work in a conceptual way suggests that they may have been shown a procedure for writing extended facts. Figure 7 has samples from Students IHA and OST showing how some students were able to explain extended facts in terms of 
the idea of 'times as many'. It also has samples from Students FWI and PME showing how students typically recorded their extended number facts.

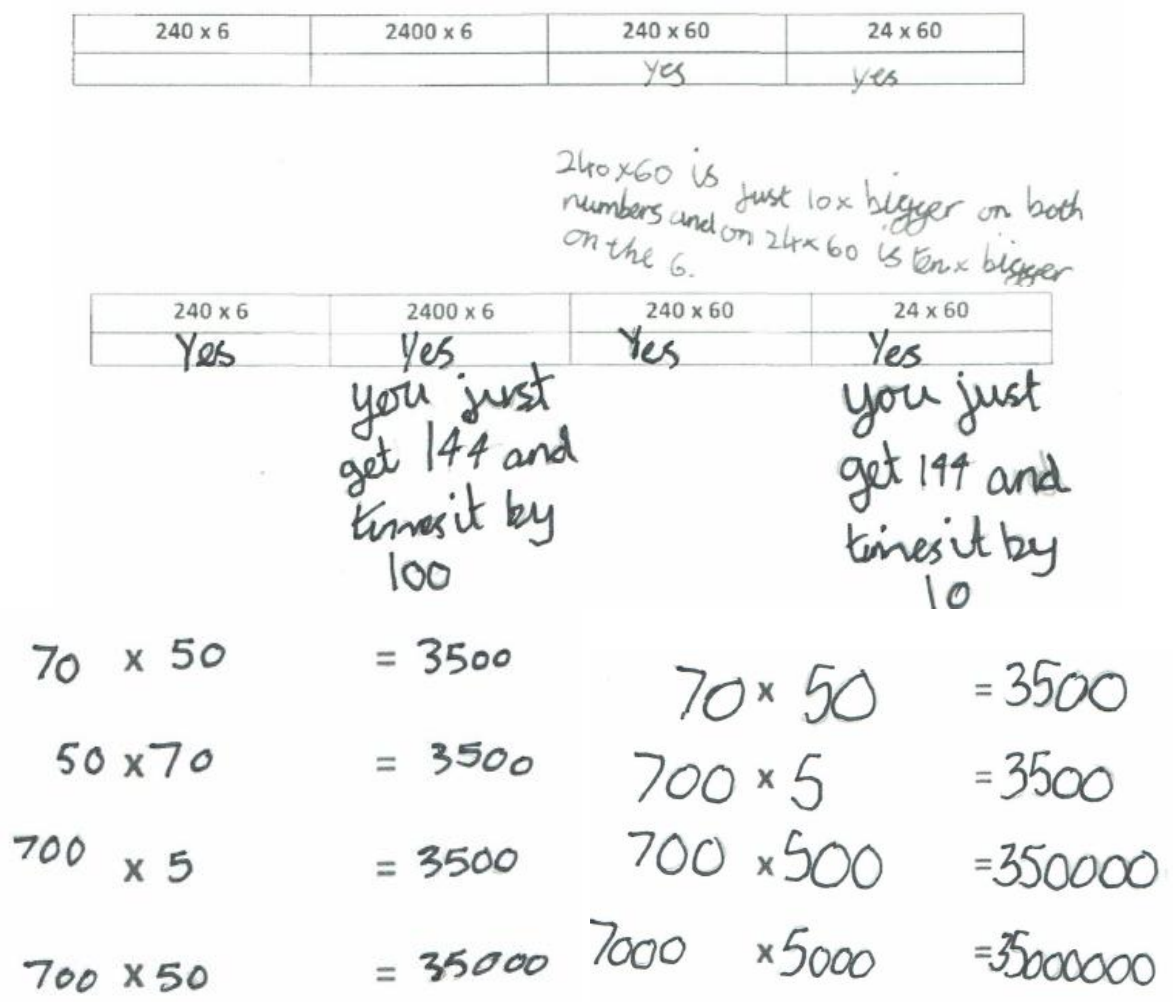

Figure 7. Samples from Students IHA, OST, FWI, and PME

\section{Multiplication algorithm}

The majority of students in the sample, $87 \%$ of Year $5 \mathrm{~s}$ and $71 \%$ of Year $6 \mathrm{~s}$, correctly calculated the answer to $29 \times 37$. Of the 15 Year 5 students, two were unable to do the calculation, two used a grid method, one used a partial product method based on partitioning, and 10 used the standard algorithm. One student who used the algorithm also did the calculation using a grid method. Of the Year 6 students, 15 used the standard algorithm and six were unable to complete it. Both the Year 5 students (GPO and MAU) who used a grid method, which is based on partitioning, also correctly used partitioning to complete the one-digit by two-digit multiplication calculations in the earlier MTQ question $(6 \times 17$ or $9 \times 15)$. Figure 8 contains samples of their work, as well as that of RCO. She used a partial product method, also based on partitioning. RCO had also correctly used partitioning in the earlier MTQ question.

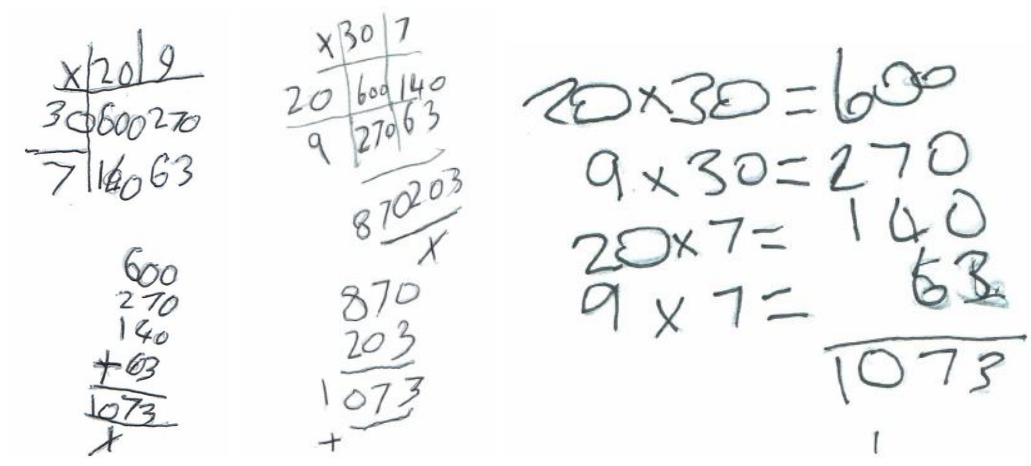

Figure 8. Samples from Students GPO, MAU, and RCO 
Students who correctly used an algorithm recorded their working in a range of ways. Some reversed the order of the numbers, some recorded the numbers they 'carried', and one student (WBL) used a four-line algorithm. If students wrote the larger number on top, they were asked why they did so. All responded, 'I always do it that way', or 'Because it's easier that way'. All who did so agreed that it made no difference to the answer, which suggests they understood of the commutative property of multiplication. Some examples of students' use of the algorithm are contained in Figure 9.

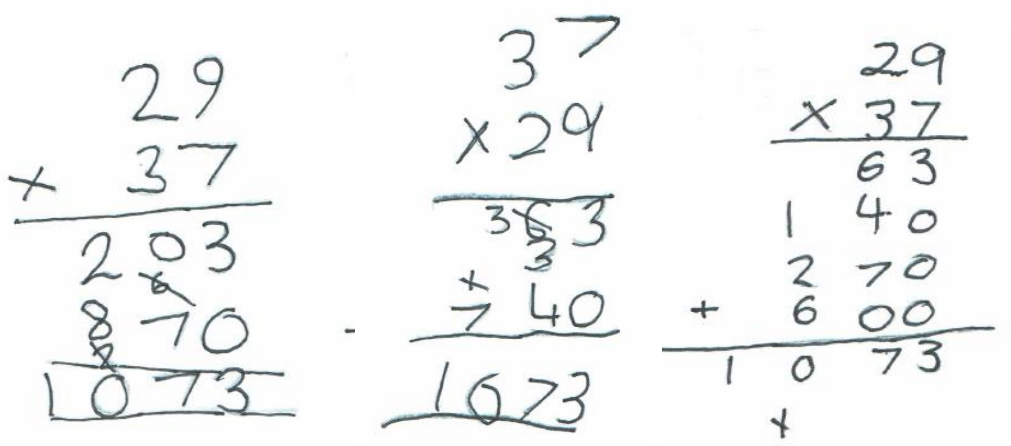

Figure 9. Samples from Students DAT, OST, and WBL

There is considerable variation in the proportion of correct responses to the MTQ questions and the ability of students to calculate the answer to $29 \times 37$. Hence, it is important to consider the structural connections between the ideas assessed in the MTQ questions and how they underpin the written multiplication algorithm. We will consider the students in two groups - the 28 students (13 Year 5 and 15 Year 6) who correctly completed the calculation for $29 \times 37$, and the eight students who did not do so.

Use of the array to show $4 \times 3$

Of the 13 Year 5 students who performed a correct calculation for $29 \times 37$, ten drew an array for $4 \times 3$ and of the 15 Year 6 students, six drew an array. It was noted earlier that the proportion of Year 6 students who drew an array was less than for the Year $5 \mathrm{~s}$ and it was suggested that this might be due to a progressive lessening in the use of the array with older students. However, as discussed earlier (Benson et al., 2013; Matney \& Daugherty, 2013), the array underpins the distributive property which in turn underpins the grid method and written multiplication algorithm. It is possible that these students have been taught to use the algorithm without being exposed to its progressive development from the array to the grid method.

\section{Partitioning}

All of the Year 5 students who performed a correct calculation for $29 \times 37$ used place value partitioning for the $6 \times 17$ and/or $9 \times 15$ calculations and all but one of the Year $6 \mathrm{~s}$ (Student JCA) did so. Students have likely been able to master either the algorithm, gird method, or partial product method because of their understanding of partitioning (YoungLoveridge \& Mills, 2009). One student (JGI) partitioned the 17 in the example but calculated incorrectly. Also, JCA did not use an array nor did he partition correctly, but he successfully completed the calculation for $29 \times 37$ with an algorithm. JCA was unable to identify or explain the distributive property, and was unable to identify, explain, or generate extended number facts (Ross, 2002). He is likely to have learned the algorithm as a procedure (Haylock, 2014). 


\section{Distributive property}

Of the 28 students (13 Year 5 and 15 Year 6) who performed a correct calculation for $29 \times 37,17$ correctly identified the two applications of the distributive property. Further to that, only 11 were able to explain that the distributive property is based on partitioning. This seems to be inconsistent with responses to the MTQ questions involving partitioning which 27 of the 28 students used to calculate the answer for $6 \times 17$ and/or $9 \times 15$. Ten of the students who used partitioning did not apply it to identifying examples of distributivity and 16 of them were unable to make the connection that the distributive property is based on partitioning (Kaminski, 2002).

\section{Extended multiplication facts}

Students need to understand and generate extended number facts to be able to use a grid method or multiplication algorithm beyond a procedural level. However, only half of the students (14) who correctly calculated for $29 \times 37$ correctly identified that all four examples in the MTQ question could be generated from $24 \times 6=144$. Even fewer students (10) were able to explain why extended number facts can be written in terms of the product being increased by a power of ten for each time a factor is increased in that way. Yet, well over half of the group (20) were able to write at least three extended multiplication facts. This has likely enabled them to use a grid method or algorithm successfully and it also suggests that students may have been taught how to write extended facts but not necessarily taught why they work. It is also worth noting that half of the students who have correctly used the grid method or algorithm were unable to identify extended facts and even less understand why they work, yet they use them in the grid method and algorithm (Hurst \& Hurrell, 2018a, 2018b).

\section{Patterns in individual responses}

When responses from individual students are analyzed, no clear pattern emerges. Only one student out of 36 (IHA) responded correctly to all seven criteria in Table 1 and also correctly calculated an answer for $29 \times 37$. Four other students correctly responded to six criteria, but they were different criteria - two did not explain the distributive property, one did not use an array for $4 \times 3$, and one did not write any extended number facts (Jazby \& Pearn, 2015). A similar situation occurred with the six students who responded correctly to five criteria and the five students who responded correctly to four criteria - no two sets of responses were the same. Table 2 shows the frequency of students who correctly calculated an answer for $29 \times 37$ and responded correctly to varying numbers of criteria.

Table 2

Frequency of correct responses to criteria based on MTQ questions

\begin{tabular}{lllllllll}
\hline $\begin{array}{l}\text { Number of } \\
\text { responses }\end{array}$ & & 6 & 5 & 4 & 3 & 2 & 1 & 0 \\
Number of students & $\mathbf{1}$ & $\mathbf{4}$ & $\mathbf{6}$ & $\mathbf{5}$ & $\mathbf{7}$ & $\mathbf{4}$ & $\mathbf{0}$ & $\mathbf{1}$ \\
\hline
\end{tabular}

With regard to the eight students who did not correctly calculate an answer for $29 \times 37$, three of them used an array to show $4 \times 3$, six used partitioning to calculate an answer for 6 $\times 17$ and/or $9 \times 15$, and two provided a set of extended number facts. One student (JDA) had three correct responses to the criteria, three responded correctly to two criteria, and two made one correct response. None of the eight students identified or explained the distributive property or extended multiplication facts.

Several things are immediately evident. The majority of students correctly used a written computation method to arrive at an answer for $29 \times 37$. Most used the standard 
vertical multiplication algorithm. Many of the students also demonstrated awareness and/or understanding of some of the mathematical structures that underpin the use of algorithms, but only one student demonstrated that awareness/understanding for all of the criteria. Indeed, some students correctly used the algorithm but demonstrated an awareness/understanding of very few of the criteria. It is not clear what this indicates and there are a few possibilities. It could be that students have learned the algorithm as a procedure and have not been specifically taught the underpinning mathematics. For instance, it might be that the array's progression to the grid method, and then to the algorithm has not been followed. Students might have been taught about some of the underpinning mathematics (e.g., partitioning) but that this has not been explicitly connected to other aspects (e.g., the distributive property).

There appears to be no particular pattern in students' responses to questions based on the criteria in Table 1. That is, very few students know about (or don't know about) the same set of criteria as other students. Hence, it is possible that teaching may not have focused on making the connections between ideas explicit to the students and that students certainly had not realized the connections for themselves. Nonetheless, it can be said that, in general, students who correctly use the algorithm or grid method, know about more of the underpinning mathematical structure than students who are unable to use the algorithm or grid method.

Most students used place value partitioning in mental and/or written computation of one digit by two-digit multiplication expressions. This includes students who were unable to use a written method for $29 \times 37$. However, slightly less than half of the students could identify and explain the distributive property, yet this is actually based on partitioning. Clearly, they had not made that conceptual connection. Also, the distributive property underpins both the grid method and standard multiplication algorithm, which many students used in spite of not showing an understanding of distributivity. Perhaps this suggests that the algorithm has been taught as a procedure, although the students who did know about the distributive property applied it correctly in their use of the algorithm or grid method. Another interesting observation is that a number of students worked out the part products for the distributivity question before recording a 'Yes' or 'No' response. This suggests that they did not know about the property would work and might not have been explicitly taught it.

The majority of students did not identify or explain extended multiplication facts. However, the majority of students were able to generate a set of extended facts. It is possible that they have been taught a procedure for writing extended facts, but it is not clear what that might be, though some students did say that 'a zero has been added'.

\section{Implications}

It is important for children to be able to form a conceptual understanding of the ideas that underpin the use of mathematical processes such as the written algorithm for multiplication. Hurst \& Huntley $(\underline{2018}$, p. 67) noted that ". . the mathematics should be explicitly taught to emphasize connections between ideas ... [and if done] ... “... it might be possible for students to avoid becoming' prisoners of process"'. Downton, Russo, \& Hopkins (2019, p. 242) noted Skemp's (1976) work noting that their findings "suggest that the teaching of rules without reason is still a contemporary issue".

It is evident that some implications exist in terms of teaching. First, the multiplicative array needs to be seen as the vehicle for understanding the connection between place value partitioning and the distributive property. Second, it follows that an extended array gives rise to the grid method of multiplication, which when combined with an understanding of 
place value partitioning and extended number facts, informs the understanding and development of the multiplication algorithm. Third, the importance of using mathematical terminology, in this case 'partitioning', is evident. This is reflected in discussions noted

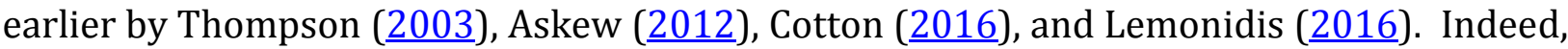
if these above aspects are understood, students are more likely to trust that the distributive property will work when applied correctly and are better placed to be able to apply it to algebraic reasoning.

\section{Conclusion}

The understanding and correct use of the standard multiplication algorithm are underpinned by several aspects of mathematical structure - the array, place value partitioning, the distributive property of multiplication, and extended multiplication facts. In this paper, we have sought to learn about the extent to which 36 primary school students understand those aspects of structure and how that understanding, or lack of it, has informed their use of written multiplication methods.

It is acknowledged that the sample size is relatively small but some interesting observations can be made. These observations would need to be tested by using the instruments with a larger sample of children in perhaps a different context. Based on the analysis of data from the MTQ and the interview, it would seem that there are several levels of understanding shown by students in the sample. These could broadly be described as follows:

- Students who can identify and explain all or most of the mathematical structure that underpins written multiplication and can correctly use a written method for multiplication.

- Students who can identify and explain some of the mathematical structure that underpins written multiplication and can correctly use a written method for multiplication.

- Students who can identify and explain little of the mathematical structure that underpins written multiplication and can correctly use a written method for multiplication.

- Students who can identify and explain little of the mathematical structure that underpins written multiplication and are unable to correctly use a written method for multiplication.

\section{Acknowledgment}

The authors acknowledge the participation of the children in this study and thank their teachers and principal for their willing involvement and support during the study.

\section{Bibliography}

Anthony, G., \&Walshaw, M. (2009). Effective pedagogy in mathematics. Belley, France: United Nations Educational, Scientific and Cultural Organisation. Retrieved from: http://www.ibe.unesco.org/publications.htm

Askew, M. (2012). Transforming primary mathematics. Abingdon, U.K.: Routledge.

Australian Curriculum, Assessment, Reporting Authority (ACARA). (2020). The Australian Curriculum: Mathematics, $\quad \mathrm{v}$ 8.3. Retrieved from http://www.australiancurriculum.edu.au/mathematics/key-ideas 
Benson, C.C., Wall, J.T., \&Malm, C. (2013). The distributive property in Grade 3? Teaching Children Mathematics, $19(8)$, 498-506. https://doi.org/10.5951/teacchilmath.19.8.0498

Clark, F. B., \& Kamii, C. (1996). Identification of multiplicative thinking in children in grades 1-5. Journal for Research in Mathematics Education, 27(1), 41-51.

Cotton, T. (2016). Understanding and teaching primary mathematics. (3 ${ }^{\text {rd }}$ ed.) Abingdon, U.K.: Routledge.

Downton, A., Russo, J., \& Hopkins, S. (2019). The case of the disappearing and reappearing zeros: A disconnection between procedural knowledge and conceptual understanding. 2019. In G. Hine, S. Blackley, \& A. Cooke (Eds.). Mathematics Education Research: Impacting Practice (Proceedings of the 42nd annual conference of the Mathematics Education Research Group of Australasia) pp. 236-243. Perth: MERGA.

Haylock, D. (2014). Mathematics explained for primary teachers. (4th. ed.). London: Sage.

Hurst, C. (2017). Children have the capacity to think multiplicatively, as long as . . . European Journal of STEM Education, 2(3), 1-14. https://doi.org/10.20897/ejsteme/78169

Hurst, C., \& Huntley, R. (2018). Algorithms and multiplicative thinking: Are children 'prisoners of process'? International Journal for Mathematics Teaching and Learning, 19(1), 47-68.

Hurst, C., \& Hurrell, D. (2018a). Algorithms are useful: Understanding them is even better. Australian Primary Mathematics Classroom, 23(3), 17-21.

Hurst, C., \& Hurrell, D. (2018b). Algorithms are great: What about the mathematics that underpins them? Australian Primary Mathematics Classroom, 23(3), 22-26.

Hurst, C., \& Hurrell, D. (2016). Multiplicative thinking: much more than knowing multiplication facts and procedures. Australian Primary Mathematics Classroom, 21(1), 34-38.

Hurst, C., \& Hurrell, D. (2014). Developing the big ideas of number. International Journal of Educational Studies in Mathematics, 1(2) 1-18. https://doi.org/10.17278/ijesim.2014.02.001

Jazby, D., \&Pearn, C. (2015). Using alternative multiplication algorithms to offload cognition. In M. Marshman, V. Geiger, \& A. Bennison (Eds.). Mathematics education in the margins (Proceedings of the 38th annual conference of the Mathematics Education Research Group of Australasia), pp. 309-316. Sunshine Coast: MERGA.

Kaminski, E. (2002). Promoting mathematical understanding: umber sense in action. Mathematics Education Research Journal, 14(2), 133-149. https://doi.org/10.1007/BF03217358

Kinzer, C.J., \& Stanford, T. (2013). The distributive property: The core of multiplication. $\begin{array}{llll}\text { Teaching } \quad \text { Children 20(5), 302-309. } & \text { Mathematics, }\end{array}$ https://doi.org/10.5951/teacchilmath.20.5.0302

Lemonidis, C. (2016). Mental computation and estimation: Implications for mathematics education research, teaching and learning. Abingon, U.K.: Routledge.

Matney, G.T., \& Daugherty, B.N. (2013). Seeing spots and developing multiplicative sense making. Mathematics Teaching in the Middle School, 19(3), 148-155. https://doi.org/10.5951/mathteacmiddscho.19.3.0148

National Governors Association Center for Best Practices, Council of Chief State School Officers (NGA Center). (2010). Common core state standards for mathematics. Retrieved from; http://www.corestandards.org/the-standards 
Norton, S., \& Irvin, J. (2007). A concrete approach to teaching symbolic algebra. In J. Watson $\&$ K. Beswick (Eds). Proceedings of the 30th annual conference of the Mathematics Education Research Group of Australasia (pp. 551-560). Hobart: MERGA.

Pickreign, J, \& Rogers, R. (2006). Do you understand your algorithms? Mathematics Teaching in the Middle School 12(1), 42-47.

Richland, L. E., Stigler, J. W., Holyoak, K. J. (2012). Teaching the Conceptual Structure of $\begin{array}{lll}\text { Mathematics, Educational } & \text { Psychologist } & 47(3),\end{array}$ https://doi.org/10.1080/00461520.2012.667065

Rittle-Johnson, B., \& Schneider, M. (2015). Developing conceptual and procedural knowledge in mathematics. In R. Cohen Kadosh\& A. Dowker (Eds.), Oxford handbook of numerical cognition (pp. 1102-1118). Oxford, UK: Oxford University Press.

Rittle-Johnson, B., Fyfe, A.M., \& Loehr, E.R. (2016). Improving Conceptual and Procedural Knowledge: The Impact of Instructional Content Within A Mathematics Lesson. British $\begin{array}{lll}\text { Journal of Educational } & \text { 85ychology. }\end{array}$ https://doi.org/10.1111/bjep.12124

Ross, S. (2002). Place value: Problem solving and written assessment. Teaching Children Mathematics, 8(7), 419-423.

Siemon, D., Breed, M., Dole, S., Izard, J., \&Virgona, J. (2006). Scaffolding Numeracy in the Middle Years - Project Findings, Materials, and Resources, Final Report submitted to Victorian Department of Education and Training and the Tasmanian Department of Education, $\quad$ Retrieved from http://www.eduweb.vic.gov.au/edulibrary/public/teachlearn/student/snmy.ppt

Siemon, D., Bleckly, J. and Neal, D. (2012). Working with the Big Ideas in Number and the Australian Curriculum: Mathematics. In B. Atweh, M. Goos, R. Jorgensen \& D. Siemon, (Eds.). (2012). Engaging the Australian National Curriculum: Mathematics Perspectives from the Field. Online Publication: Mathematics Education Research Group of Australasia pp. 19-45.

Skemp, R. (1976). Relational understanding and instrumental understanding. Mathematics Teaching 77 (20-26).

Squire, S., Davies, C., \& Bryant, P. (2004). Does the cue help? Children's understanding of multiplicative concepts in different problem contexts. British Journal of Educational Psychology, 74, (515-532). https://doi.org/10.1111/bjep.12124

Thompson, I. (2003). Place value: the English disease? In I. Thompson, (Ed.). Enhancing Primary Mathematics Teaching. Berkshire, U.K.: Open University Press, pp. 181-190.

Turton, A. (Ed.). (2007). The Origo handbook of mathematics education. Brisbane: Origo.

Young-Loveridge, J. (2005) Fostering multiplicative thinking using array-based materials. Australian Mathematics Teacher, 61 (3), 34-40.

Young-Loveridge, J., \& Mills, J. (2009). Teaching multi-digit multiplication using array based materials. In R. Hunter, B. Bicknell, \& T. Burgess (Eds.), Crossing divides: Proceedings of the 32nd annual conference of the Mathematics Education Research Group of Australasia (Vol. 2). PalmerstonNorth, NZ: MERGA. 